\title{
Brain Imaging: The Chemistry of Mental Activity
}

Henry N. Wagner, Jr.

London, U.K.: Springer, 2008, 246 pages, $\$ 169$

This interesting book first explains the technical and scientific details of molecular neuroimaging and then links to the clinical aspects of neurologic and mental disorders. The author expands the scope in 2 directions. One direction is to go further from the technical aspects to relate to genetic events. The other direction is to reach logical explanations for mental activities: social behaviors such as love, aggression, war, and genocide. The author concludes the book by arriving at an emphasis on ethical concerns about managing modern technology. Being able to noninvasively study human mental activities, neuroimaging is the apt nexus to these different disciplines.

Although the main theme is nuclear imaging of the brain, this book is also intended to reach a broad audience. Imagers, neuroscientists, and the general public will benefit from reading it. Some of the historic events and detailed scientific findings that are described will indeed serve as good reminders for practitioners in neuroimaging. Imagers and neuroscientists will also appreciate the way neuroimaging is shown to relate to far-reaching social phenomena. As for the public, the author lays out nuclear imaging historically and traces the advances that he built and witnessed. He has made the key events of neuroimaging easy for the public to understand and relate to social and historic events.

The 19 chapters are well referenced and logically arranged. It is not easy to put together a book of 235 pages that covers the grand scope of scientific advances in neuroimaging over the last 4 decades and the related social events, as well as ethical concerns. The author has managed to bring important issues out in each chapter and still keep the audience interested to the end of the book. It is definitely well worth reading, whether for imagers, students of liberal arts, or the public. Being one of the students mentioned in the dedication of this book, I have again taken a couple more lessons from Dr. Wagner.

Franklin C. Wong

M.D. Anderson Cancer Center

Houston, Texas 